\title{
Article \\ Low-Frequency Oscillations and Force Control Capabilities as a Function of Force Level in Older Women
}

Nyeonju Kang (D)

check for updates

Citation: Kang, N. Low-Frequency Oscillations and Force Control Capabilities as a Function of Force Level in Older Women. Appl. Sci. 2022, 12, 1812. https://doi.org/ 10.3390/app12041812

Academic Editor: Joung Hwan Mun

Received: 19 December 2021

Accepted: 9 February 2022

Published: 10 February 2022

Publisher's Note: MDPI stays neutral with regard to jurisdictional claims in published maps and institutional affiliations.

Copyright: (C) 2022 by the author. Licensee MDPI, Basel, Switzerland. This article is an open access article distributed under the terms and conditions of the Creative Commons Attribution (CC BY) license (https:// creativecommons.org/licenses/by/ $4.0 /)$
Division of Sport Science, Neuromechanical Rehabilitation Research Laboratory, Health Promotion Center, and Sport Science Institute, Incheon National University, Incheon 22012, Korea; nyunju@inu.ac.kr; Tel.: +82-32-835-8573

\begin{abstract}
Force variability is potentially related to altered low-frequency oscillations in motor outputs. This study examines the contributions of low-frequency oscillations in force to altered force control performances from lower to higher targeted force levels in older women. Fourteen older women executed unilateral hand-grip force control tasks at $10 \%$ and $40 \%$ of maximum voluntary contraction (MVC). Force control performances were estimated by calculating force accuracy (rootmean-square-error), force variability (standard deviation), and force regularity (approximate entropy). We additionally quantified low-frequency oscillations in force using absolute powers across four different frequency bands: (a) $0-0.5 \mathrm{~Hz}$, (b) $0.5-1.0 \mathrm{~Hz}$, (c) $1.0-1.5 \mathrm{~Hz}$, and (d) $1.5-2.0 \mathrm{~Hz}$. The findings reveal that from lower to higher targeted force level older women show greater force error, force variability, and force regularity with increased values of absolute power in force across the four frequency bands. The multiple regression models identified a significant relationship between greater force frequency power below $0.5 \mathrm{~Hz}$ and more impairments in force control performances. These findings suggest that force frequency oscillation below $0.5 \mathrm{~Hz}$ is a key predictor indicating altered stability of task performances across different targeted force levels in older women.
\end{abstract}

Keywords: force control; low-frequency oscillations; force level; women; aging

\section{Introduction}

Force control capabilities are essential for successfully conducting various activities of daily living [1,2]. Moreover, the isometric force control paradigm may be a viable option to estimate sensorimotor integration functions in the motor system [3,4] because a performer can produce and maintain isometric forces around the targeted force level via continuous online motor corrections by processing visual feedback. During the isometric force control task, quantifying inconsistency of motor outputs (i.e., force variability) provides information regarding how the motor system controls and regulates motor-related neural oscillations for successful task performance [5-7].

A recent literature review raised the possibility that force variability properties in the motor system may be associated with changes in the low-frequency oscillations of motor outputs [8]. For healthy young adults, when the concurrent visual information was removed, force oscillations below $0.5 \mathrm{~Hz}$ increased with greater force variability during the index finger's abduction force control tasks [9]. Moreover, older adults and patients with stroke revealed more low force oscillations with higher motor variability than those in the control groups $[9,10]$. While processing a greater amount of visual information (i.e., higher visual gain conditions), elderly people especially elevated force frequency properties below $0.5 \mathrm{~Hz}$ that predicted more force variability across force control tasks using upper and lower limbs [9,11]. Interestingly, these greater force oscillations below $0.5 \mathrm{~Hz}$ were additionally associated with increased oscillation of muscle activity below $0.5 \mathrm{~Hz}$ (i.e., EMG burst power) for both younger and older adult groups [11,12]. Taken together, these findings support an idea that force frequency power below $0.5 \mathrm{~Hz}$ may be a crucial predictor indicating altered neuromuscular variability in the motor system. 
A recent literature review proposed several possible mechanisms underlying the relationship between the greater powers in the low-frequency band and increased force variability [8]. Potentially, the central nervous system (CNS) may select a control strategy for increasing the efficiency in controlling and generating more accurate force outputs by grouping the activations in the motor neuron pools into a low-frequency unit. Next, the low-frequency oscillations in forces may be considered as neuronal noise that presumably originated from higher physiological stress in the sympathetic nervous system (e.g., breathing and heart rate) [13]. Finally, the altered voluntary drive from the brain when more difficult task requirements were provided $[9,12,14]$ may be responsible for the low force frequency oscillations.

Importantly, force control performances can be affected by various neuromuscular factors such as different targeted force levels. For example, force variability (i.e., standard deviation of force outputs) typically increased at higher targeted force levels $[15,16]$. Given that this scaling relation between force variability and targeted force level presumably reflects neuronal changes in the central and peripheral nervous systems [17-19], increased force variability at higher targeted force levels would be influenced by greater force oscillations below $0.5 \mathrm{~Hz}$. In fact, a prior study reported that increased force variability from $10 \%$ to $30 \%$ of maximum voluntary contraction (MVC) in healthy young adults was significantly associated with greater force frequency power below $0.5 \mathrm{~Hz}$ [12]. Previously, older adults revealed higher force variability than young adult controls across various submaximal targeted force levels (e.g., $10-50 \%$ of MVC) because of age-related deficits in the nervous systems $[16,20]$. Force control at higher targeted levels is necessary to facilitate greater neural involvements in the motor system (e.g., hyperactivation across sensorimotor cortex and greater low-frequency oscillations in motor neuron discharge rates) [21,22]. However, given that elderly people showed a tendency to increase the neural activations to compensate for age-related impairments in the motor system [23], controlling degrees of freedom of neural resources may be challenging for older adults, resulting in more erroneous and variable forces [24]. Taken together, these findings suggest that elderly people may additionally show greater force oscillations below $0.5 \mathrm{~Hz}$ from lower to higher targeted force levels that potentially lead to more impairments in force control capabilities.

Thus, the purpose of this study is to investigate the effects of different force levels on changes in force control performances and low-frequency oscillations in force for older adults. In particular, we focused on older women since females in the older group demonstrated more impairments in hand-grip force control performances than males [25] because of the interactive effects of aging and loss of sexual hormones facilitating more dysfunctions in the motor system [26]. Participants executed unilateral hand-grip force control tasks with their dominant hand at $10 \%$ and $40 \%$ of MVC. Beyond the previous findings that focused on force variability changes [8-11], we additionally examined the potential contribution of low-frequency oscillations in force to various force control performances, including force accuracy, variability, and regularity. Based on a significant relationship between greater powers in the low force frequency band $(<0.5 \mathrm{~Hz})$ and increased force variability [8], we hypothesized that force control performances (i.e., greater task error, variability, and regularity) would be impaired from lower to higher targeted force levels, and furthermore the increased force oscillations below $0.5 \mathrm{~Hz}$ would be associated with more force control impairments.

\section{Materials and Methods}

\subsection{Participants}

Fourteen healthy older right-handed women who experienced menopause (time since menopause $>$ six years) participated in this study. Before the testing, we confirmed that all participants had no musculoskeletal deficits in their upper extremities and cognitive dysfunctions (mini-mental state examination scores $\geq 26$ ) [27]. Specific demographic details are shown in Table 1. All participants read and signed the study protocols and an 
informed consent form approved by the Institutional Review Board of the Incheon National University prior to beginning the experiments.

Table 1. Demographic information.

\begin{tabular}{lc}
\hline Characteristics & Older Women \\
\hline Sample Size (N) & 14 \\
\hline Age (years) & $63.5 \pm 2.4$ \\
Time since menopause (year) & $13.2 \pm 5.3$ \\
Handedness & 14 right handed \\
Weight (kg) & $58.9 \pm 6.2$ \\
Skeletal Muscle Mass (kg) & $20.1 \pm 1.7$ \\
Body Fat Mass (kg) & $21.4 \pm 4.5$ \\
BMI (\%) & $24.1 \pm 2.3$ \\
\hline Mini-mental state exam (score) & $28.1 \pm 1.7$ \\
\hline Data were stated as mean \pm standard deviation. BMI: body mass index. &
\end{tabular}

\subsection{Experimental Apparatus and Procedures}

Hand-grip force control tasks for the dominant hand were administered because grip strength is progressively reduced in the aging population $[28,29]$, and further decreased grip strength predicts various age-related diseases [30]. Participants sat in front of a $54.6 \mathrm{~cm}$ LED monitor $(1920 \times 1080$ pixels and $60 \mathrm{~Hz}$ of a refresh rate) located $80 \mathrm{~cm}$ away at eye level and placed both arms on the table with comfortable positions (15-20 of shoulder flexion and $25-40^{\circ}$ of elbow flexion). To perform grip force control tasks, participants used their dominant hands and maintained their non-dominant hands on the pad (Figure 1A). To avoid unintentional force generations caused by other joint actions, we instructed them to fix both arms on the table during the task execution. We used a customized isometric force control device (SEED TECH Co., Ltd., Bucheon, South Korea), including handles (a diameter $=30 \mathrm{~mm}$ ) embedded force transducers (Micro Load Cell-CZL635-3135, range $=220$ lbs., Phidgets Inc., Calgary, Canada). A 16-bit analog-to-digital converter (A/D; ADS1148 16-Bit 2Ksps and a minimum detectable force $=0.0192 \mathrm{~N}$ ) collected all force signals (a sampling rate $=200 \mathrm{~Hz}$ ) amplified by an INA122 with an excitation voltage of $5 \mathrm{~V}$ (Texas Instruments Inc., Dallas, TX, USA). All experimental procedures were administered using a custom Microsoft Visual C++ program (Microsoft Corp., Redmond, WA, USA), and a custom Matlab Program (Math Works ${ }^{\mathrm{TM}}$ Inc., Natick, MA, USA) was used for additional offline analysis.

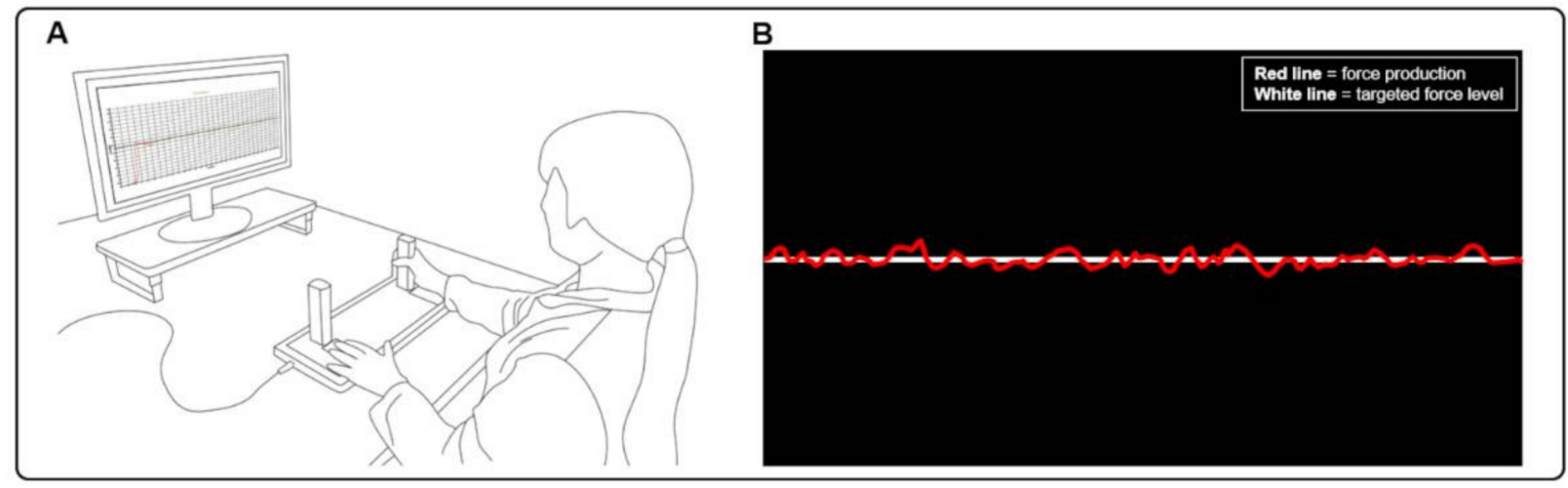

Figure 1. Experimental setup. (A) hand-grip isometric force control, and (B) visual information during force control task.

\subsubsection{MVC task}

To set individualized targeted force levels, participants conduced two consecutive MVC trials. We instructed participants to produce their maximal forces for $5 \mathrm{~s}$ and provided 
$60 \mathrm{~s}$ of rest between MVC trials. We selected a peak value of force outputs for each trial, and calculated participant's MVC by averaging the two peak values. Then, two levels of targeted force levels (i.e., $10 \%$ and $40 \%$ of MVC) for each participant were calculated.

\subsubsection{Submaximal Force Control Task}

We administered three consecutive submaximal force control trials for each targeted force level (i.e., $10 \%$ and $40 \%$ of MVC). The order of the two targeted force levels was randomly assigned. During a submaximal force control trial, participants produced and maintained isometric force outputs around the targeted force level for $20 \mathrm{~s}$. Two types of visual information were provided on the screen: (a) isometric force production $=$ a red line, and (b) targeted force level $=$ a white line (Figure 1B). To minimize potential fatigue effects, we set $30 \mathrm{~s}$ of rest between trials and $60 \mathrm{~s}$ of rest between targeted force levels.

\subsection{Data Analysis}

To prevent potential initial isometric force control adjustment and early termination effects, the first $5 \mathrm{~s}$ and final $1 \mathrm{~s}$ of force data were removed. Thus, the middle $14 \mathrm{~s}$ of force data was analyzed for each trial. Using a bidirectional fourth-order Butterworth filter (a cutoff frequency $=30 \mathrm{~Hz}$ ), all force data were additionally filtered. Force control performances were estimated by (a) force accuracy: root-mean-square error (RMSE), (b) force variability: standard deviation (SD), and (c) force regularity: approximate entropy (ApEn). Force regularity is a temporal structure of force variability so that ApEn values denote regularity of future force signals in a time series in comparison to the prior force signals. The values of ApEn close to 2 represent less regularity of force data indicating more adaptive force productions, whereas the values of ApEn close to 0 mean more regularity of force data. Using the Pincus algorithm (Formula 1), we calculated the ApEn value for each trial $[31,32]$.

$$
\operatorname{ApEn}(\vec{X}, m, r)=\ln \left[\frac{C_{m}(r)}{C_{m+1}(r)}\right]
$$

where $C_{m}(r)$ indicates number of repetitive patterns of length $\mathrm{m}$ of vector $X$ within $r$ criterion of similarity. $C_{m}+1(r)$ indicates number of repetitive patterns of length $m+1$. Consistent with previous studies [33,34], we set $m$ as 2 and $r$ as $0.2 \times$ SD.

Low-frequency oscillations in force signals were calculated by performing power spectrum analysis with a fast Fourier transform using a custom Matlab Program (Math Works ${ }^{\mathrm{TM}}$ Inc., Natick, MA, USA). Consistent with prior studies [11,12], we quantified absolute power $\left(\mathrm{N}^{2}\right)$ for the four frequency bands: (a) $0-0.5 \mathrm{~Hz}$, (b) $0.5-1.0 \mathrm{~Hz}$, (c) $1.0-1.5 \mathrm{~Hz}$, and (d) $1.5-2.0 \mathrm{~Hz}$.

\subsection{Statistical Analysis}

To determine altered force control performances across different targeted force levels, we conducted paired $t$-tests on RMSE, SD, and ApEn. Furthermore, two-way ANOVA with repeated measures on each factor (Force Level $\times$ Frequency Band; $2 \times 4$ ) were used for the low-frequency oscillations in force signals. When assumptions of sphericity were violated, we report Greenhouse-Geisser's degrees of freedom adjustment. Bonferroni pairwise comparisons were used for the post hoc test. To determine the relationship between altered low-frequency oscillations in force and force control performances between two targeted force levels, we performed three multiple linear regression analyses on changes in absolute powers for each frequency band (four explanatory variables at $40 \%$ of MVC-those at $10 \%$ of MVC) and changes in force control performance (a dependent variable at $40 \%$ of MVC - those at 10\% of MVC) using the stepwise method. Both explanatory and dependent variables were the changes in variables from lower to higher targeted force levels. All statistical analyses were conducted using the IBM SPSS Statistics 22 (SPSS Inc., Chicago, IL, USA) and the alpha level was set at 0.05 . 


\section{Results}

\subsection{Force Control Performance and Low-Frequency Oscillations in Force}

From $10 \%$ to $40 \%$ of MVC, paired $t$-tests revealed impairments in force control performances: (a) increased values in RMSE $\left(t_{13}=-10.215 ; p<0.001\right.$; Figure 2A), (b) greater values in SD ( $t_{13}=-8.239$ and $p<0.001$; Figure $\left.2 \mathrm{~B}\right)$, and (c) less values in ApEn $\left(t_{13}=12.247\right.$ and $p<0.001$; Figure 2C). Moreover, a two-way repeated measures ANOVA on the absolute power showed a significant force level $\times$ frequency band interaction $[F(1.882,24.468)=25.675$; $p<0.001$; partial $\eta^{2}=0.664$; Figure 2D]. Post hoc analyses showed that the absolute power for four frequency bands significantly increased from $10 \%$ to $40 \%$ of MVC. At $10 \%$ of MVC, the absolute power in $0.5-1.0 \mathrm{~Hz}$ was significantly greater than those in $1.5-2.0 \mathrm{~Hz}$ and the absolute power in 1.0-1.5 Hz was significantly greater than those in 1.5-2.0 Hz. At 40\% of $\mathrm{MVC}$, the absolute powers were significantly different among all pairs of frequency bands.

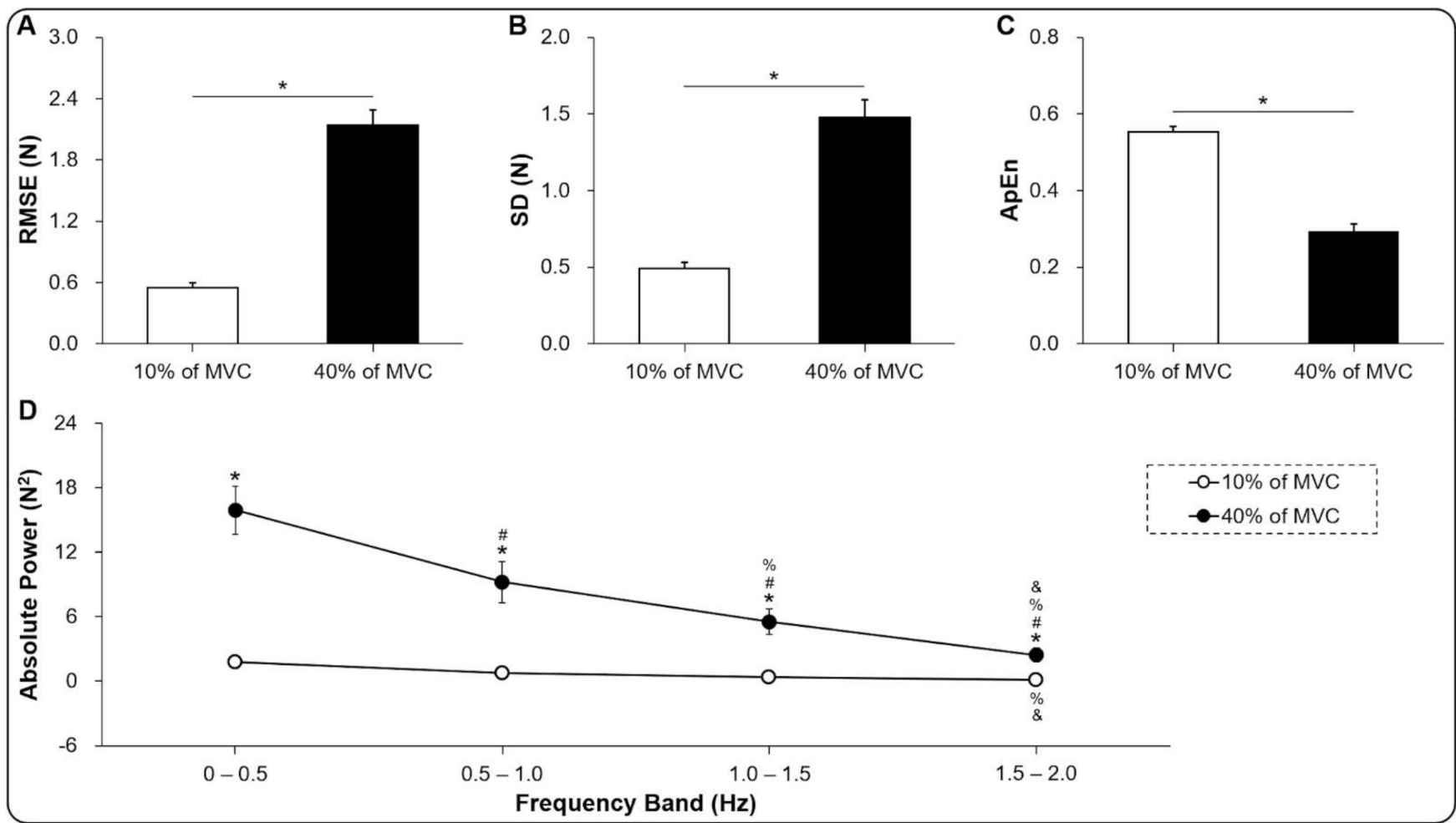

Figure 2. Force control performances and low-frequency oscillations in force across two targeted force levels. (A) Force accuracy (RMSE), (B) force variability (SD), (C) force regularity (ApEn), and (D) low-frequency oscillations in force (absolute power) for four frequency bans as a function of different targeted force level. Data are mean \pm standard error. Asterisk ${ }^{*}$ ) denotes a significant difference between two targeted force levels. Number sign (\#) indicates a significant difference in comparison to $0-0.5 \mathrm{~Hz}$. Percent sign (\%) indicates a significant difference in comparison to $0.5-1.0 \mathrm{~Hz}$. Ampersand (\&) means a significant difference in comparison to $1.0-1.5 \mathrm{~Hz}$.

\subsection{Relationship between Changes in Low-Frequency Oscillations in Force and Force Control Performances across Different Targeted Force Levels}

A multiple linear regression analysis using a stepwise method identified a significant relationship between increased values of absolute power in $0-0.5 \mathrm{~Hz}$ and higher RMSE values $\left(\mathrm{Y}=0.920+0.047 \mathrm{X} ; R^{2}=0.533 ; p=0.003\right.$; Figure $\left.3 \mathrm{~A}\right)$. For $\mathrm{SD}$ values, the analysis found a significant relationship between increased values of absolute power in $0-0.5 \mathrm{~Hz}$ and $0.5-1.0 \mathrm{~Hz}$ and higher SD values $\left(\mathrm{Y}=0.307+0.037 \mathrm{X}_{0-0.5 \mathrm{~Hz}}+0.018 \mathrm{X}_{0.5-1.0 \mathrm{~Hz}} ; R^{2}=0.978\right.$; $p<0.001$; Figure 3B). Finally, a multiple linear regression analysis using a stepwise method reported a significant relationship between increased values of absolute power in $0-0.5 \mathrm{~Hz}$ and less ApEn values ( $\mathrm{Y}=-0.141-0.008 \mathrm{X} ; R^{2}=0.890 ; p<0.001$; Figure $\left.3 \mathrm{C}\right)$. 


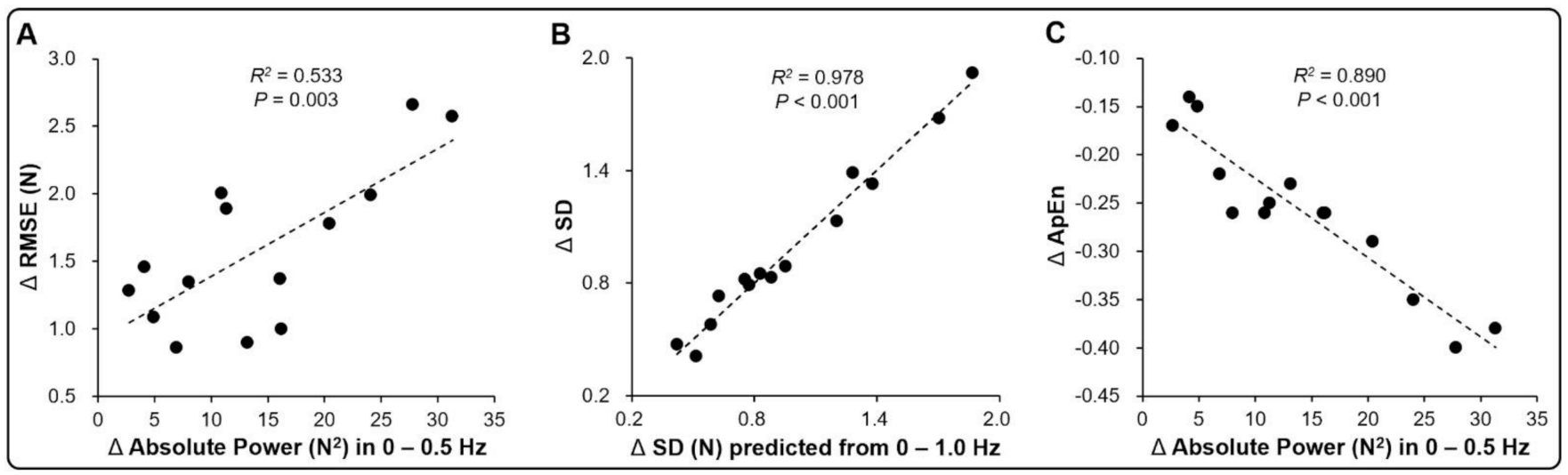

Figure 3. Regression models showing relationship between change of low-frequency oscillations in force and force control performances across two targeted force levels. (A) force frequency oscillations below $0.5 \mathrm{~Hz}$ (absolute power in $0-0.5 \mathrm{~Hz}$ ) vs. force accuracy (RMSE), (B) force frequency oscillations below $1.0 \mathrm{~Hz}$ (absolute powers in $0-0.5 \mathrm{~Hz}$ and $0.5-1.0 \mathrm{~Hz}$ ) vs. force variability (SD), and (C) force frequency oscillations below $0.5 \mathrm{~Hz}$ (absolute power in $0-0.5 \mathrm{~Hz}$ ) vs. force regularity (ApEn).

\section{Discussion}

The current study examines altered low-frequency oscillations in force and force control performances across different targeted force levels in older women. From 10\% to $40 \%$ of MVC, older women increased force error, force variability, and force regularity during unilateral hand-grip force control tasks, and further revealed greater force oscillations in four different frequency bands below $2 \mathrm{~Hz}$. Interestingly, the multiple linear regression analyses using a stepwise method identified that greater amounts of force oscillations below $0.5 \mathrm{~Hz}$ significantly predicted higher levels of force error, force variability, and force regularity from lower to higher targeted force levels, respectively.

\subsection{Changes in Force Control Capabilities and Low-Frequency Oscillations at Different Targeted Levels}

Not surprisingly, older women revealed force control deficits such as increased force error and absolute force variability at $40 \%$ of MVC as compared with those at $10 \%$ of MVC consistent with most prior findings [12,15,16,35]. Presumably, simultaneously maintaining and correcting force outputs via the processing of visual information at higher targeted levels is challenging so that these procedures required more neural involvements in the motor system, such as greater brain activation across sensorimotor areas and low-frequency oscillations in motor neuron discharge rates [21,22]. Importantly, the neural involvements for the elderly people tended to increase to compensate for age-related impairments in the motor system [23]. These greater neural resources during the task may increase difficulty in controlling the degrees of freedom of motor actions for the older adults, resulting in more erroneous and variable forces [24]. Moreover, higher force regularity at $40 \%$ of MVC than at $10 \%$ of MVC is in line with previous studies [16,36,37]. The prior findings indicated that the motor system may decrease motor adaptations (e.g., increased motor optimality) rather than identify various motor options (e.g., increased motor flexibility) while performing more difficult tasks (e.g., tasks that required stronger force productions and tasks without visual feedback) [37,38].

Beyond the prior findings that showed the contribution of low-frequency oscillations in force signals to force variability [8], we found that these relationship patterns were observed in both force accuracy and regularity across different targeted force level. A recent study reported that increased relative force power below $0.25 \mathrm{~Hz}$ was significantly associated with higher task error $\left(R^{2}=0.36\right)$ and force variability $\left(R^{2}=0.33\right)$ when healthy young participants executed more challenging dynamic force control tasks (i.e., tracking $1 \mathrm{~Hz}$ of the sinusoidal target line than $0.5 \mathrm{~Hz}$ of the sinusoidal target line) [14]. Common findings from two studies that focused on healthy young adults suggested that task constraints 
(e.g., more difficult task requirements such as higher targeted force level and more oscillatory targeted force level) influenced changes in the low force frequency band $(<0.5 \mathrm{~Hz})$ resulting in impaired force control performances [12,14]. Taken together, we confirmed that the potential effects of task constraint on low-frequency oscillation in force signals additionally appeared in the older women group in addition to the young adults [12].

Interestingly, the current findings expanded prior findings by showing a significant relationship between force frequency power below $0.5 \mathrm{~Hz}$ and force regularity across different targeted force levels. Christou and colleagues posited that greater force oscillations below $0.5 \mathrm{~Hz}$ may be related to the CNS's motor control strategies [8,14]. When higher force outputs are generated, a greater number of spinal motor neurons are recruited [39]. For example, producing and controlling isometric force outputs at a higher targeted force level ( $>30 \%$ of MVC) may require the recruitment of large motor neurons that innervate fast-twitch, fatigable muscle fibers, in addition to the early recruitment of small motor neurons that innervate slow-twitch muscle fibers [39]. Thus, the CNS is necessary to control numerous spinal motor neurons in an efficient way (i.e., grouping spinal motor neurons into low-frequency units) that may increase force frequency power below $0.5 \mathrm{~Hz}$ instead of individually modulating spinal motor neurons. In fact, a prior simulation study found that motor unit synchronization patterns, defined as a tendency for comparable temporal intervals of discharge rate between motor units, increased with more efforts toward producing forces leading to deterioration of motor actions (e.g., greater force variability and low force frequency oscillations) [40]. Dideriksen and colleagues additionally reported simulated results that more regular force generation patterns (i.e., lower values of ApEn) appeared with a greater number of motor neurons involvements [41]. Importantly, the inter-spike intervals in aging muscles tended to be less complex (i.e., higher regularity), and furthermore elderly people hardly continued task stability along with more flexibility [42]. Overall, this motor control strategy may be responsible for producing more stereotyped motor outputs (i.e., increased force regularity) rather than generating more flexible force control.

\subsection{Potential Mechanisms underlying the Contribution of Low-Frequency Oscillations to Force Control Capabilities}

Potentially, the effects of changes in low force frequency oscillations on force control performances may originate from neural involvements of the central and peripheral nervous systems. Given that producing stronger muscle forces increased corticomuscular coherences across various frequency bands (e.g., beta and gamma bands) [43], greater low-frequency oscillations at higher targeted force level may be influenced by voluntary drive from supraspinal level to activations in the spinal motor neurons [8]. Moreover, despite no muscle activation findings in this study, several studies reported a potential relationship between whole muscle activity oscillations in the gamma band and low-frequency burst $(<1 \mathrm{~Hz})$ in muscle activity contributing to a force frequency structure below $0.5 \mathrm{~Hz}$ $[11,12,14]$. Intriguingly, several studies have focused on low-frequency oscillations of brain activity (i.e., electroencephalogram: EEG frequency power below $0.5-4 \mathrm{~Hz}$ ) that potentially appeared in specific pathologies (e.g., epileptic seizure, attention deficit hyperactivity disorder, and stroke) [44-46]. Indeed, a recent study that examined postural variability during a forward lean task reported greater low-frequency of center of pressure (COP) oscillations below $0.5 \mathrm{~Hz}$ in the older adult group than in the young adult group, and furthermore found these changes were associated with greater COP variability collapsed across the two groups [47]. Presumably, low-frequency oscillations of various biological signals may be related to motor variability in human movements. Thus, future studies should determine whether low-frequency oscillations in force signals are the results of intentional motor control strategies from the brain or inherent noise components of biological signals in the motor system. 


\subsection{Study Limitations}

Although we identified the relationship between low-frequency oscillations and force control capabilities in older women, these findings should be carefully interpreted. First, given that only older women participated in this study, whether changes in force oscillation below $5 \mathrm{~Hz}$ from $10 \%$ to $40 \%$ of MVC are different between younger and older adult groups is still inconclusive. Previously, older adults revealed greater force oscillations below $5 \mathrm{~Hz}$ with higher motor variability than those in younger adults while processing a greater amount of visual feedback [9], and furthermore a lower mean firing rate of motor units appeared in older adults during submaximal force control tasks (10-50\% of MVC) [48]. Thus, comparing altered low-frequency oscillations between younger and older groups across different targeted force levels may provide further information regarding age-related motor control deficits. Moreover, some studies that used conventional surface EMG devices evidenced that low-frequency oscillations in muscle activity were associated with force frequency power below $0.5 \mathrm{~Hz}[12,14]$. Beyond these findings, to determine potential relationship between altered motor neuron pools and force frequency oscillations below $0.5 \mathrm{~Hz}$ caused by aging, future studies should examine low-frequency properties of multiple motor units activations and force control capabilities between younger and older adults according to various task constraints.

\section{Conclusions}

In summary: the current study identifies that increased force frequency oscillations below $0.5 \mathrm{~Hz}$ in older women are significantly associated with more impairments in force control performances from lower to higher targeted force levels. Our findings expand prior results shown in healthy young individuals [12] by demonstrating the effects of increased force frequency oscillations below $0.5 \mathrm{~Hz}$ on impaired force control capabilities estimated by both conventional (higher force error and variability) and non-linear (greater force regularity) measurements. These findings suggest that impaired force control capabilities from lower to higher targeted force levels may originate from changes in low force frequency properties regardless of the aging progress. Moreover, in addition to recent findings that show greater force frequency oscillations below $0.5 \mathrm{~Hz}$ with higher visual gain condition in older adults [11], we suggest that low-frequency oscillation in force is a key predictor indicating altered stability of task performances in elderly people affected by various task requirements.

Funding: This research was funded by a National Research Foundation of Korea (NRF) grant funded by the Korean government (MSIT), Grant Number NRF-2018R1C1B5084455.

Institutional Review Board Statement: The study was conducted according to the guidelines of the Declaration of Helsinki and approved by the Institutional Review Board of Incheon National University (approval \#7007971-201810-002A and the study protocol was approved on 16 December 2020).

Informed Consent Statement: Informed consent was obtained from all subjects involved in the study.

Data Availability Statement: Not Available.

Acknowledgments: Not Available.

Conflicts of Interest: The authors declare no conflict of interest.

\section{References}

1. Wang, D.X.M.; Yao, J.; Zirek, Y.; Reijnierse, E.M.; Maier, A.B. Muscle mass, strength, and physical performance predicting activities of daily living: A meta-analysis. J. Cachexia Sarcopenia Muscle 2020, 11, 3-25. [CrossRef]

2. Kang, N.; Cauraugh, J.H. Force control in chronic stroke. Neurosci. Biobehav. Rev. 2015, 52, 38-48. [CrossRef] [PubMed]

3. Slifkin, A.B.; Vaillancourt, D.E.; Newell, K.M. Intermittency in the control of continuous force production. J. Neurophysiol. 2000, 84, 1708-1718. [CrossRef]

4. Vieluf, S.; Sleimen-Malkoun, R.; Voelcker-Rehage, C.; Jirsa, V.; Reuter, E.-M.; Godde, B.; Temprado, J.-J.; Huys, R. Dynamical signatures of isometric force control as a function of age, expertise, and task constraints. J. Neurophysiol. 2017, 118, 176-186. [CrossRef] 
5. Vaillancourt, D.E.; Thulborn, K.R.; Corcos, D.M. Neural basis for the processes that underlie visually guided and internally guided force control in humans. J. Neurophysiol. 2003, 90, 3330-3340. [CrossRef]

6. Archer, D.B.; Kang, N.; Misra, G.; Marble, S.; Patten, C.; Coombes, S.A. Visual feedback alters force control and functional activity in the visuomotor network after stroke. NeuroImage Clin. 2017, 17, 505-517. [CrossRef] [PubMed]

7. Harris, C.M.; Wolpert, D.M. Signal-dependent noise determines motor planning. Nature 1998, 394, 780-784. [CrossRef]

8. Lodha, N.; Christou, E.A. Low-frequency oscillations and control of the motor output. Front. Physiol. 2017, 8, 78. [CrossRef] [PubMed]

9. Fox, E.J.; Baweja, H.S.; Kim, C.; Kennedy, D.M.; Vaillancourt, D.E.; Christou, E.A. Modulation of force below 1 Hz: Age-associated differences and the effect of magnified visual feedback. PLoS ONE 2013, 8, e55970. [CrossRef] [PubMed]

10. Lodha, N.; Misra, G.; Coombes, S.A.; Christou, E.A.; Cauraugh, J.H. Increased force variability in chronic stroke: Contributions of force modulation below $1 \mathrm{~Hz}$. PLoS ONE 2013, 8, e83468. [CrossRef]

11. Park, S.H.; Kwon, M.; Christou, E.A. Motor output oscillations with magnification of visual feedback in older adults. Neurosci. Lett. 2017, 647, 8-13. [CrossRef]

12. Moon, H.; Kim, C.; Kwon, M.; Chen, Y.T.; Onushko, T.; Lodha, N.; Christou, E.A. Force control is related to low-frequency oscillations in force and surface EMG. PLoS ONE 2014, 9, e109202. [CrossRef] [PubMed]

13. Christou, E.A.; Jakobi, J.M.; Critchlow, A.; Fleshner, M.; Enoka, R.M. The 1- to 2-Hz oscillations in muscle force are exacerbated by stress, especially in older adults. J. Appl. Physiol. 2004, 97, 225-235. [CrossRef] [PubMed]

14. Park, S.H.; Kim, C.; Yacoubi, B.; Christou, E.A. Control of oscillatory force tasks: Low-frequency oscillations in force and muscle activity. Hum. Mov. Sci. 2019, 64, 89-100. [CrossRef] [PubMed]

15. Slifkin, A.B.; Newell, K.M. Noise, information transmission, and force variability. J. Exp. Psychol. Hum. Percept. Perform. 1999, 25, 837-851. [CrossRef]

16. Vieluf, S.; Temprado, J.-J.; Berton, E.; Jirsa, V.K.; Sleimen-Malkoun, R. Effects of task and age on the magnitude and structure of force fluctuations: Insights into underlying neuro-behavioral processes. BMC Neurosci. 2015, 16, 12. [CrossRef]

17. Jones, K.E.; Hamilton, A.F.D.C.; Wolpert, D.M. Sources of signal-dependent noise during isometric force production. J. Neurophysiol. 2002, 88, 1533-1544. [CrossRef]

18. Ward, N.S.; Swayne, O.B.C.; Newton, J.M. Age-dependent changes in the neural correlates of force modulation: An fMRI study. Neurobiol. Aging 2008, 29, 1434-1446. [CrossRef]

19. Mayhew, S.D.; Porcaro, C.; Tecchio, F.; Bagshaw, A.P. fMRI characterisation of widespread brain networks relevant for behavioural variability in fine hand motor control with and without visual feedback. NeuroImage 2017, 148, 330-342. [CrossRef]

20. Sorond, F.A.; Cruz-Almeida, Y.; Clark, D.J.; Viswanathan, A.; Scherzer, C.R.; De Jager, P.; Csiszar, A.; Laurienti, P.J.; Hausdorff, J.M.; Chen, W.G.; et al. Aging, the central nervous system, and mobility in older adults: Neural mechanisms of mobility impairment. J. Gerontol. Ser. A Boil. Sci. Med. Sci. 2015, 70, 1526-1532. [CrossRef]

21. Cramer, S.C.; Weisskoff, R.M.; Schaechter, J.D.; Nelles, G.; Foley, M.; Finklestein, S.P.; Rosen, B.R. Motor cortex activation is related to force of squeezing. Hum. Brain Mapp. 2002, 16, 197-205. [CrossRef] [PubMed]

22. Dideriksen, J.L.; Negro, F.; Enoka, R.M.; Farina, D. Motor unit recruitment strategies and muscle properties determine the influence of synaptic noise on force steadiness. J. Neurophysiol. 2012, 107, 3357-3369. [CrossRef] [PubMed]

23. Noble, J.W.; Eng, J.J.; Kokotilo, K.J.; Boyd, L.A. Aging effects on the control of grip force magnitude: An fMRI study. Exp. Gerontol. 2011, 46, 453-461. [CrossRef]

24. Christou, E.A. Aging and variability of voluntary contractions. Exerc. Sport Sci. Rev. 2011, 39, 77-84. [CrossRef] [PubMed]

25. Choi, K.-H.; Kim, D.-M.; Lee, S.-Y.; Lee, J.-H.; Kong, Y.-K. Evaluation of the controlled grip force exertion tasks associated with age, gender, handedness and target force level. Int. J. Occup. Saf. Ergon. 2017, 24, 507-515. [CrossRef] [PubMed]

26. Messier, V.; Rabasa-Lhoret, R.; Barbat-Artigas, S.; Elisha, B.; Karelis, A.D.; Aubertin-Leheudre, M. Menopause and sarcopenia: A potential role for sex hormones. Maturitas 2011, 68, 331-336. [CrossRef]

27. Folstein, M.F.; Folstein, S.E.; McHugh, P.R. "Mini-mental state". A practical method for grading the cognitive state of patients for the clinician. J. Psychiatr. Res. 1975, 12, 189-198. [CrossRef]

28. Mehmet, H.; Yang, A.W.H.; Robinson, S.R. Measurement of hand grip strength in the elderly: A scoping review with recommendations. J. Bodyw. Mov. Ther. 2020, 24, 235-243. [CrossRef]

29. Kurina, L.M.; Gulati, M.; Everson-Rose, S.A.; Chung, P.J.; Karavolos, K.; Cohen, N.J.; Kandula, N.; Lukezic, R.; Dugan, S.A.; Sowers, M.; et al. The Effect of menopause on grip and pinch strength: Results from the Chicago, Illinois, site of the study of women's health across the nation. Am. J. Epidemiol. 2004, 160, 484-491. [CrossRef] [PubMed]

30. Li, Y.-Z.; Zhuang, H.-F.; Cai, S.-Q.; Lin, C.-K.; Wang, P.-W.; Yan, L.-S.; Lin, J.-K.; Yu, H.-M. Low grip strength is a strong risk factor of osteoporosis in postmenopausal women. Orthop. Surg. 2018, 10, 17-22. [CrossRef]

31. Pincus, S.M. Approximate entropy as a measure of system complexity. Proc. Natl. Acad. Sci. USA 1991, 88, 2297-2301. [CrossRef] [PubMed]

32. Pincus, S.M.; Goldberger, A.L. Physiological time-series analysis: What does regularity quantify? Am. J. Physiol. 1994, 266, H1643-H1656. [CrossRef]

33. Vaillancourt, D.E.; Slifkin, A.B.; Newell, K.M. Regularity of force tremor in Parkinson's disease. Clin. Neurophysiol. 2001, 112, 1594-1603. [CrossRef] 
34. Cauraugh, J.H.; Lodha, N.; Naik, S.K.; Summers, J.J. Bilateral movement training and stroke motor recovery progress: A structured review and meta-analysis. Hum. Mov. Sci. 2010, 29, 853-870. [CrossRef] [PubMed]

35. Strote, C.; Gölz, C.; Stroehlein, J.K.; Haase, F.K.; Koester, D.; Reinsberger, C.; Vieluf, S. Effects of force level and task difficulty on force control performance in elderly people. Exp. Brain Res. 2020, 238, 2179-2188. [CrossRef]

36. Mosconi, M.W.; Mohanty, S.; Greene, R.K.; Cook, E.H.; Vaillancourt, D.E.; Sweeney, J.A. Feedforward and feedback motor control abnormalities implicate cerebellar dysfunctions in autism spectrum disorder. J. Neurosci. 2015, 35, 2015-2025. [CrossRef] [PubMed]

37. Hu, X.; Loncharich, M.; Newell, K.M. Visual information interacts with neuromuscular factors in the coordination of bimanual isometric force. Exp. Brain Res. 2011, 209, 129-138. [CrossRef] [PubMed]

38. Gorniak, S.L. The relationship between task difficulty and motor performance complexity. Atten. Percept. Psychophys. 2019, 81, 12-19. [CrossRef]

39. Conwit, R.A.; Stashuk, D.; Tracy, B.; McHugh, M.; Brown, W.F.; Metter, E.J. The relationship of motor unit size, firing rate and force. Clin. Neurophysiol. 1999, 110, 1270-1275. [CrossRef]

40. Yao, W.; Fuglevand, R.J.; Enoka, R.M. Motor-unit synchronization increases EMG amplitude and decreases force steadiness of simulated contractions. J. Neurophysiol. 2000, 83, 441-452. [CrossRef]

41. Dideriksen, J.; Elias, L.A.; Zambalde, E.P.; Germer, C.M.; Molinari, R.G.; Negro, F. Influence of central and peripheral motor unit properties on isometric muscle force entropy: A computer simulation study. J. Biomech. 2021, 110866. [CrossRef] [PubMed]

42. Chen, Y.-C.; Lin, L.L.; Hwang, I.-S. Novel behavioral and neural evidences for age-related changes in force complexity. J. Gerontol. Ser. A 2018, 73, 997-1002. [CrossRef] [PubMed]

43. Liu, J.; Sheng, Y.; Liu, H. Corticomuscular coherence and its applications: A review. Front. Hum. Neurosci. 2019, 13, 100. [CrossRef] [PubMed]

44. Demanuele, C.; James, C.J.; Sonuga-Barke, E.J. Distinguishing low frequency oscillations within the $1 / \mathrm{f}$ spectral behaviour of electromagnetic brain signals. Behav. Brain Funct. 2007, 3, 62. [CrossRef]

45. Ramanathan, D.S.; Guo, L.; Gulati, T.; Davidson, G.; Hishinuma, A.K.; Won, S.-J.; Knight, R.T.; Chang, E.F.; Swanson, R.A.; Ganguly, K. Low-frequency cortical activity is a neuromodulatory target that tracks recovery after stroke. Nat. Med. 2018, 24, 1257-1267. [CrossRef] [PubMed]

46. Cassidy, J.M.; Wodeyar, A.; Wu, J.; Kaur, K.; Masuda, A.K.; Srinivasan, R.; Cramer, S.C. Low-frequency oscillations are a biomarker of injury and recovery after stroke. Stroke 2020, 51, 1442-1450. [CrossRef]

47. Delmas, S.; Watanabe, T.; Yacoubi, B.; Christou, E.A. Age-associated increase in postural variability relate to greater low-frequency center of pressure oscillations. Gait Posture 2021, 85, 103-109. [CrossRef]

48. Connelly, D.M.; Rice, C.L.; Roos, M.R.; Vandervoort, A.A. Motor unit firing rates and contractile properties in tibialis anterior of young and old men. J. Appl. Physiol. 1999, 87, 843-852. [CrossRef] [PubMed] 